\title{
AVALIAÇÃO ERGONÔMICA EM UM VIVEIRO FLORESTAL DE SANTA MARIA, RS
}

\author{
Gessieli Possebom ${ }^{1}$; Antonio Robson Moreira ${ }^{1}$, Dauto Piveta Carpes $^{1}$, Tiago Rodrigo Francetto ${ }^{1}$, Bruno Christiano Corrêa Ruiz Zart ${ }^{1}$, \\ Pablo do Amaral Alonço ${ }^{1}$, Airton dos Santos Alonço ${ }^{1}$
}

1 Departamento de Engenharia Rural, Universidade Federal de Santa Maria, 97105-900, Santa Maria, Brasil.

*E-mail: gessielip@hotmail.com

Recebido em: 15/08/2016 Aceito em: 12/09/2016

\section{RESUMO}

O estudo foi desenvolvido com base nos dados coletados em um viveiro florestal em Santa Maria, com o objetivo de realizar uma avaliação postural dos trabalhadores e das condições ambientais e estruturais do local de trabalho. A avaliação ocorreu a partir de observações visuais, além de registros fotográficos e posterior análise postural através do método RULA pelo Software Ergolân dia. Ainda, utilizou-se de entrevista informal e o censo de ergonomia de COUTO para aferições acerca dos trabalhadores do viveiro. Através das análises, evidenciou-se que as posturas empregadas no total de atividades avaliadas no viveiro não se encontram adequadas, resultando no nível 3 do método RULA, sendo necessário, portanto, intervenção ergonômica. Corroborando com tais resultados, evidenciou-se dor e desconforto nos trabalhadores, especialmente na região de coluna, pescoço, pernas e braços dos trabalhadores. O ambiente de trabalho estudado também não é condizente com o adequado para a execução das tarefas, ocasionando insatisfação entre os trabalhadores. Assim, para melhoria do ambiente, saúde e segurança, recomenda-se o uso de bancadas que permitam posturas corretas para a execução das atividades, utilização de EPIs durante as operações, evitar transporte de cargas excessivas, além de manter o revezamento de funções, diminuindo o risco de lesões por atividades repetitivas.

Palavras-chave: Análise Postural; RULA; Segurança.

\section{Introdução}

O setor de florestas plantadas no Brasil vem sofrendo uma expansão considerável desde a última década. Destacandose especialmente as espécies dos gêneros Pinus e Eucaliptus, os plantios comerciais totalizam 6,5 milhões de hectares, com uma taxa de crescimento anual de $3,5 \%$. Na sociedade, tem sua importância ainda em termos econômicos e sociais, sendo responsável, em 2011, por um valor bruto de produção de R \$ 51,8 bilhões [1].

No sistema florestal, a produção em viveiro constitui a primeira etapa do processo, tornando-se o principal setor responsável pela oferta das mudas que farão parte de plantações comerciais, reflorestamentos, arborização urbana, entre outras finalidades [2]. Apesar da relevância, as operações que envolvem o preparo das mudas e implantação florestal, ainda em sua maioria são desenvolvidas de forma manual ou semimecanizada e sem condições ergonômicas apropriadas, expondo os trabalhadores a equipamentos perigosos, elevados esforços físicos e posturas inadequadas [3].
Dependendo da forma como essas atividades são efetuadas, os trabalhadores ainda muitas vezes, erguem e transportam cargas com peso acima dos limites toleráveis, na forma incorreta e continuadamente por vários anos, aumentando riscos de lesão no trabalho [4]. Em virtude desse panorama, temse aumentado a preocupação com a saúde e segurança dos trabalhadores, buscando melhorias no ambiente laboral, criando assim condições para que não se perca produtividade.

As condições do local de trabalho, bem como as variáveis ambientais presentes devem ser as mais agradáveis possíveis, a fim de proporcionar o melhor relacionamento entre a empresa e o empregado, pois, quando desfavoráveis, podem provocar exaustão, extenuação física e nervosa, diminuindo o rendimento e a qualidade do trabalho e, consequentemente aumentar os erros e riscos de acidentes [5]. Nesse sentido, a análise ergonômica do trabalho se insere como uma importante ferramenta, objetivando a adaptação do trabalho ao homem, através da análise da tarefa, da postura e dos movimentos do operador, assim como de suas exigências físicas e psicológicas. Torna-se mais relevante na medida em que permite analisar não 
somente a relação do operador com o sistema de produção, mas também à relação de cada posto de trabalho com o operador [6].

Em viveiros, a ergonomia atua especialmente para amenizar a fadiga dos trabalhadores e melhorar as condições de trabalho e segurança, resultando no aumento de produtividade do sistema, além de contribuir para a satisfação pessoal e profissional dos envolvidos [4]. Dessa forma, o presente estudo teve por objetivo realizar uma avaliação postural dos trabalhadores, bem como levantar aspectos ambientais e condições de trabalho de um viveiro florestal em Santa Maria, subsidiando a tomada de decisão para a melhoria das condições de conforto, saúde e segurança dos trabalhadores.

\section{Parte Experimental ou Metodologia}

\subsection{Localização e caracterização do estudo}

O estudo foi realizado no Viveiro Florestal da Universidade Federal de Santa Maria (UFSM), localizado a $29^{\circ} 43^{\prime} 13.4^{\prime}$ ' S e 53 43'12.9' W, município de Santa Maria, RS, em maio de 2016. Criado na década de 70, o viveiro pertence ao Departamento de Ciências Florestais da UFSM e tem por objetivo o Ensino, Pesquisa e Extensão, com enfoque na produção de sementes e mudas quase que essencialmente para cunho acadêmico.

O levantamento de informações gerais do viveiro e referentes às funções dos trabalhadores se deu através de uma entrevista informal. O horário de funcionamento geral do viveiro compreende das $07 \mathrm{~h} 30 \mathrm{~min}$ às $11 \mathrm{~h} 30 \mathrm{~min}$ e das $13 \mathrm{~h} 00 \mathrm{~min}$ às 17h00min, sendo desempenhadas por um contingente de 18 pessoas, distribuídos em: 4 trabalhadores efetivos, 1 professora, 5 acadêmicos de graduação e 8 acadêmicos de pós-graduação. A professora, além da função de ministrar aulas para graduação e pós-graduação, é a responsável pela coordenação do setor, orientação de alunos da pós-graduação e de iniciação científica e supervisão das atividades desenvolvidas no viveiro.

Dentre os quatro funcionários efetivos atuantes no viveiro, um membro é o responsável pelo setor administrativo, desenvolvendo atividades de contabilidade e, uma funcionária é a responsável pelo setor de serviços gerais, desenvolvendo atividades de limpeza e organização em toda a área do viveiro florestal. Os demais funcionários (dois) eram incumbidos das tarefas de produção de mudas e cuidados do viveiro, executando um revezamento de funções, sendo estas essencialmente: o preparo do substrato, o enchimento dos tubetes; plantio de sementes; limpeza e transporte das bandejas.

Os alunos de pós-graduação divididos em 3 mestrandos e 5 doutorandos, todos Engenheiros Florestais, desenvolvem seus estudos na área de Silvicultura. Responsáveis por auxiliarem a professora na orientação dos alunos de iniciação científica empenham-se ainda na execução de trabalhos referentes às suas dissertações e teses, além das atividades gerais do viveiro, por estarem diretamente ligadas aos seus projetos. Por fim, os alunos de iniciação científica, todos acadêmicos de Engenharia Florestal, apresentam como função auxiliar os pós-graduandos nas atividades de produção de mudas, além de prestarem auxílio nos experimentos desenvolvidos e na escrita de artigos científicos.

Para a análise ergonômica do trabalho, avaliaram-se as atividades que estavam sendo desempenhadas em um dos dias de visita, não tomando como parâmetro o funcionário ou aluno envolvido na tarefa. São elas: Monda em pleno sol e em casa de sombra; Transporte de bandejas em geral; e Análise experimental. Para tanto foi aplicado o método RULA através do Software Ergolândia 5.0, 2014, em cada uma destas atividades.

Este método consiste na avaliação da exposição dos trabalhadores a fatores de risco que podem ocasionar transtornos nos membros superiores do corpo. Para tal, é avaliado o posicionamento de braço, antebraço, punho, rotação do punho, pescoço, tronco e pernas, além de considerar a atividade a ser executada, o uso da musculatura para o desenvolvimento da atividade, bem como a carga necessária na operação.

Assim, durante a aplicação do método RULA, cada fator avaliado recebe uma pontuação de acordo com a postura empregada, obtendo como resultado final um escore entre 1 e 7 , enquadrados em 4 possíveis níveis de ação. Pontuações mais altas tendem a significar um nível de risco mais elevado, enquanto que uma baixa pontuação aparenta menor risco, conforme apresentado no Quadro 1.

Quadro 1: Resultado da intervenção ergonômica

\begin{tabular}{|c|c|l|}
\hline Pontuação & $\begin{array}{l}\text { Nível de } \\
\text { Ação }\end{array}$ & Intervenção \\
\hline 1 ou 2 & 1 & Postura aceitável \\
\hline 3 ou 4 & 2 & $\begin{array}{l}\text { Deve-se realizar uma observação } \\
\text { Podem ser necessárias mudanças }\end{array}$ \\
\hline 5 ou 6 & 3 & $\begin{array}{l}\text { Deve-se realizar uma investigação } \\
\text { Podem ser introduzidas mudanças }\end{array}$ \\
\hline 7 & 4 & $\begin{array}{l}\text { Podem ser introduzidas mudanças } \\
\text { imediatamente }\end{array}$ \\
\hline
\end{tabular}

Fonte: [7].

A coleta de dados para a avaliação postural se deu através de observações visuais aos trabalhadores durante a execução da tarefa, além de registros fotográficos das posições mais empregadas para posterior análise minuciosa e aplicação do método. Em cada uma das atividades avaliadas, foi considerando ainda os fatores ambientais influentes do local, sendo os valores obtidos através da média de três observações no decorrer da atividade. Os fatores analisados foram: Iluminação (determinado através de um Luxímetro e avaliado segundo NBR 5413 [8]); Ruído (mensurado através de um Decibelímetro e avaliado segundo NBR 10152 [9]) e Temperatura (determinado através de um Termômetro Digital e segundo a NR 15 [10]).

Para aferir sobre as condições de saúde dos trabalhadores foi utilizado o Censo de Ergonomia de Couto [11]. 
Este consiste numa ferramenta formulada à base de questionário, no qual o trabalhador expressa sua percepção a respeito do posto de trabalho e da atividade que executa. O trabalhador pode informar se sente ou não desconforto, dificuldade ou fadiga, em que intensidade, se está relacionado ou não ao trabalho que exerce e, ao mesmo tempo, fazer sugestões para melhorá-lo. Este Censo permite uma abordagem precoce de uma inadequação ergonômica, uma vez que antes de ocorrerem lesões e afastamento, o trabalhador costuma sentir desconforto, dificuldade, fadiga e mesmo dor ao realizar a atividade.

Por fim, através de observações visuais no ambiente de trabalho, foi analisado as condições ergonômicas da estrutura geral do viveiro, abrangendo a casa de sombra, a casa de vegetação fechada e com aberturas laterais e a bancada de trabalho para preparo do substrato. A partir dessas análises buscou-se evidenciar possíveis fatores que predisponham risco de lombalgia, repetitividade e necessidade ou não do uso de EPI.

\subsection{Descrição das tarefas}

O processo de análise experimental ocorre em uma área de acesso a laboratórios do viveiro florestal, onde os trabalhadores acomodam as bandejas de mudas no chão e permanecem sentados em bancos de 30 centímetros de altura. $\mathrm{O}$ ciclo operacional inicia-se com retirada da muda da bandeja, posterior medição do diâmetro e altura, finalizando com a devolução da muda para a bandeja. Em relação a tarefa de monda, é realizada junto às mudas, seja em áreas a pleno sol ou em casas de sombra. O ciclo operacional se assemelha ao anterior, iniciando com a retirada da muda da bandeja, limpeza de competidores no tubete e posterior devolução a bandeja. Em ambos os casos, o procedimento é repetido até o momento em que todas as mudas passaram pelo mesmo processo, sendo então a atividade encerrada.

A tarefa de limpeza e transporte de bandejas é realizada nas proximidades do depósito, onde as bandejas são depositadas no chão. O ciclo operacional inicia-se com a lavagem das bandejas através do uso de uma mangueira e na sequência distribuição das mesmas no chão a fim de secar ao ambiente. $\mathrm{O}$ processo termina com o transporte das bandejas, onde para tal o trabalhador ergue cerca de 5 bandejas ( 3 a $4 \mathrm{~kg}$ ) conjuntamente acima da linha dos ombros, depositando-as no local apropriado.

O preparo do substrato é desenvolvido geralmente por um único trabalhador. O processo inicia com a mistura dos componentes requeridos para o substrato em uma betoneira para total homogeneização, em seguida é despejado em uma caixa e esta é então colocada sobre uma mesa de trabalho de 0,90 metros de altura. Na sequência o substrato é coletado com uma pá e depositado sobre as bandejas de tubetes. Posteriormente as bandejas são transferidas para uma mesa de vibração de 0,95 metros de altura, onde é realizada a agitação dos tubetes para acomodação do substrato. Após esse processo, as bandejas são transferidas para uma bancada com a mesma altura da mesa vibratória, onde é realizada a semeadura das espécies desejadas, encerrando o processo.

\section{Resultados e discussões}

\subsection{Análise Postural}

Os procedimentos de avaliação experimental e de monda exigem complexidade na postura empregada. $\mathrm{O}$ caráter de alta repetitivivade exigida pode determinar o aparecimento de fadiga nos trabalhadores, reduzindo a capacidade de concentração e o rendimento operacional [12]. Durante ambas as atividades é necessário constante movimento com os braços, antebraços e punhos, a fim de manipular as mudas, afastando-se da posição neutra (próximo ao tronco). Esse movimento, pode ocasionar inflamação dos nervos, resultando em dores e sensações de formigamento nos dedos e braços [13].

Mesmo que o trabalhador esteja habituado àquela função, a posição sentada compromete a coluna vertebral, uma vez que o banco utilizado não apresenta encosto, nem espaço adequado para disposição dos membros inferiores, além da tarefa apresentar o agravante da necessidade de rotação do tronco para retirada das mudas das bandejas. Quando uma tarefa é realizada adotando-se posturas inadequadas, pode ocasionar graves consequências para a saúde do trabalhador, pois a postura é considerada mais nociva quanto mais se afasta da posição de neutralidade funcional ou anatômica provocando, assim, doenças ocupacionais e lesões $[11 ; 14]$.

Em relação a limpeza e transporte de bandejas, como a atividade exige elevar os membros superiores em conjunto com a aplicação de força, novamente os braços e antebraços saem da linha neutra estabelecida, fator determinante para o aparecimento de dor e posterior doenças relacionadas ao trabalho [15]. Corroborando com tal afirmação, [14] retrata que em algumas atividades florestais geralmente os trabalhadores adotam posturas em pé, com movimentos repetitivos, manuseando cargas de elevado peso, cujas situações podem causar problemas à sua saúde.

A Tabela 1 apresenta os resultados segundo o método RULA, para essas três atividades avaliadas. Analisando os dados obtidos, observa-se que todas obtiveram a pontuação final de 5 ou 6, com nível de ação 3. Ou seja, é necessário realizar uma investigação e ser introduzidas mudanças confirmando, portanto, o emprego de posturas inadequadas durante a execução das atividades. O trabalho florestal é um importante causador de más posturas, pois algumas das tarefas executadas são realizadas na posição parada e em pé ou em movimento agachada, com movimentos repetitivos, onde os trabalhadores podem assumir posturas incorretas durante a jornada de trabalho [16]. 
Tabela 1- Resultados da análise postural, segundo o método RULA

\begin{tabular}{lcclcr}
\hline Atividade & Pontuação & $\begin{array}{c}\text { Nível de } \\
\text { Ação }\end{array}$ & \multicolumn{2}{c}{ Interpretação } & \\
\hline $\begin{array}{l}\text { Análise } \\
\text { Experimental }\end{array}$ & 5 ou 6 & 3 & $\begin{array}{l}\text { Deve-se realizar uma } \\
\text { investigação } \\
\text { Podem ser introduzidas } \\
\text { mudanças }\end{array}$ \\
\hline Monda & 5 ou 6 & 3 & $\begin{array}{l}\text { Deve-se realizar uma } \\
\text { investigação } \\
\text { Podem ser introduzidas } \\
\text { mudanças }\end{array}$ \\
\hline $\begin{array}{l}\text { Limpeza e } \\
\text { Transporte de } \\
\text { bandejas }\end{array}$ & 5 ou 6 & 3 & $\begin{array}{l}\text { Deve-se realizar uma } \\
\text { investigação } \\
\text { Podem ser introduzidas } \\
\text { mudanças }\end{array}$ \\
\hline
\end{tabular}

Corroborando com o emprego de más posturas, de acordo com a Figura 1, 80\% dos trabalhadores entrevistados informaram sentir dor ou desconforto na região do pescoço, $60 \%$ relataram desconforto nos punhos, além de $20 \%$ apontarem sentir dor na região de braços, antebraços e pernas. Porém, a coluna vertebral foi avaliada como a parte do corpo mais afetada pelas atividades, sendo informada a existência de dor por todos os trabalhadores. Durante as operações em viveiro, a coluna vertebral é um dos locais mais afetados, especialmente em atividades de plantio de eucalipto e transporte de materiais [17]. Resultados semelhantes foram obtidos por [18] e [19] ao estudarem as operações de viveiro, principalmente nas atividades de transporte de mudas, onde verificaram que as articulações dos ombros, tornozelos e coluna foram comprometidas.

Entretanto, apesar da totalidade dos trabalhadores atribuírem a dor sentida a atividades do viveiro, foi conferida uma intensidade leve também por todos os trabalhadores. Ainda, segundo $100 \%$ deles, ocorre diminuição da dor em períodos de repouso ou pausas durante as atividades. As pausas são necessárias para evitar a sobrecarga de trabalho, quando se detectam excessos de carga física. Por isso, o trabalho em metas deve ser evitado, visto que o trabalhador muitas vezes ignora as limitações do seu organismo, procurando encerrar a tarefa o mais breve possível [15].

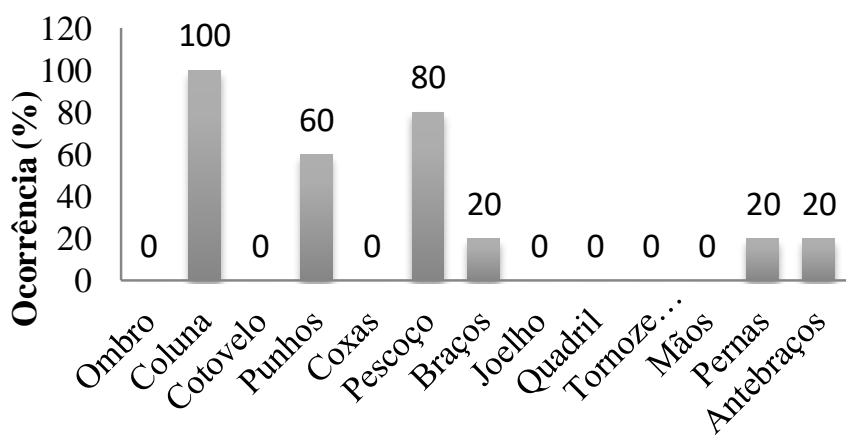

Figura 1: Ocorrência de dor em trabalhadores de um viveiro, em Santa Maria, RS.
As atividades florestais, além de exigirem posturas especificas dos trabalhadores, expõe os mesmos a diversos fatores ambientais referentes as tarefas, tornando-se importante o uso de Equipamentos de Proteção Individual (EPI). No viveiro florestal, a análise experimental e a monda são desenvolvidas sem o uso de qualquer tipo de EPIs e quando do procedimento de limpeza de bandejas apenas é utilizado botas de borracha. $\mathrm{O}$ não uso desse tipo de equipamento, expõe o corpo do trabalhador a irradiação solar, poeira, a até produtos químicos utilizados na produção das mudas, tornando-se mais um agravante para a incidência de lesões e acidentes no meio florestal.

\subsection{Análise de variáveis ambientais}

A consideração de variáveis ambientais durante a realização de um trabalho é tão importante quanto as variáveis posturais. O ruído, as vibrações, o calor, o frio, os produtos tóxicos, entre outros, quando excedem certos limites, podem provocar doenças ou alterar o bem-estar. O trabalho quando desenvolvido em um ambiente com condições climáticas desfavoráveis produz fadiga, irritação, comprometendo o rendimento e expondo o organismo a diversas doenças [11].

\subsubsection{Ruído}

O ruído é um dos fatores mais importantes a serem considerados em um ambiente de trabalho. Nos diversos segmentos de uso, ele se apresenta como indispensável para a vida moderna, contribuindo para o projeto de máquinas, equipamentos e ferramentas, bem como para detectar falhas que possam produzir danos irreparáveis. Entretanto, apesar de seus benefícios, quando usado inadequadamente, dependendo da magnitude e do tempo de exposição provoca lesões ao ser humano, podendo ser o causador de inúmeras perturbações e, com o tempo atrapalhar a audição [20].

Além disso, pode causar interferência nas comunicações entre os trabalhadores, reduzindo a concentração na atividade desenvolvida. Segundo NR 15 [10] o limite de exposição durante 8 horas de trabalho contínuo, de modo que não cause perturbação ou cause danos à saúde é de $85 \mathrm{~dB}$. Ao analisar as diferentes atividades desenvolvidas no viveiro florestal, bem como os setores de produção de mudas, verificou-se que os valores encontrados em todos os ambientes se situaram abaixo do limite máximo estabelecido, ou seja, não causando perturbações que comprometam a audição dos trabalhadores (Tabela 2).

\subsubsection{Luminosidade}

A luminosidade presente no local de trabalho é um condicionante determinante de um produto de qualidade. A intensidade da luz incidente deve ser suficiente para garantir uma boa visibilidade, permitindo que o trabalhador possa executar a 
tarefa sem dificuldades de visualização. Ainda, é importante considerar que a superfície de trabalho não permita reflexos e sombras, evitando que crie uma barreira adicional para o trabalho [20].

As atividades de análise experimental, limpeza de mudas e lavagem de bandejas, são desenvolvidas unicamente fazendo uso da luz ambiental, assim como o ambiente das casas de vegetação e casa de sombra, as quais são iluminadas com luz natural. Analisando a Tabela 2, observa-se que os valores de iluminamento para esses locais apresentam-se acima de 10.000 lux. Do mesmo modo que índices de iluminamento muito reduzidos prejudicam o desenvolvimento das atividades, níveis crescentes a partir de 1.000 lux podem proporcionar fadiga visual nos trabalhadores [6].

Em se tratando de recintos não usados em trabalho contínuo, segundo a NBR 5413 [8], é indicado o nível de 150 lux. Assim, a bancada de trabalho para preparo do substrato, como apresentou 154 lux de iluminamento, está condizente com o estabelecido pela norma e, portanto, o local se apresenta como adequado para o trabalho, nesse aspecto (Tabela 1 ).

\subsubsection{Temperatura}

O ambiente de trabalho é fortemente influenciado pela temperatura. Quando em situações extremas, o espaço torna-se desconfortável, aumentando o risco de acidentes devido às tensões causadas pelo calor ou frio e podendo interferir negativamente também no desempenho do trabalhador em relação ao produto final [21].

O trabalho em condições climáticas desfavoráveis produz fadiga, esgotamento físico e nervoso, diminuição do rendimento e aumento de erros, além de expor o organismo a diversas doenças [11]. Segundo esse mesmo autor, à medida que o meio se torna mais hostil, aumenta a preocupação do trabalhador sobre esse problema, o que afeta a sua atenção durante a atividade específica que está realizando e, consequentemente, provoca perda de eficiência e segurança no trabalho.

O trabalho realizado no viveiro florestal é considerado como contínuo, classificando como de intensidade moderado pela NR 15 [10] e, portanto, apresentando o limite de exposição ao calor de $26,7^{\circ} \mathrm{C}$. Com uma análise comparativa desse parâmetro em relação a Tabela 2 , apenas a casa de vegetação com aberturas laterais excede esse índice, sendo então necessário reduzir ao máximo o tempo de permanência nesse local.
Tabela 2: Variáveis ambientais avaliadas no viveiro florestal

\begin{tabular}{lccc}
\hline Setor do Viveiro & $\begin{array}{c}\text { Temperatura } \\
\left({ }^{\mathbf{o}} \mathbf{C}\right)\end{array}$ & $\begin{array}{c}\text { Ruído } \\
(\mathbf{d B})\end{array}$ & $\begin{array}{c}\text { Luminosidade } \\
(\mathbf{l u x})\end{array}$ \\
\hline Casa de Sombra & 20 & 65 & 10000 \\
\hline $\begin{array}{l}\text { Casa de Vegetação } \\
\text { Fechada }\end{array}$ & 24,7 & 64 & 11150 \\
\hline $\begin{array}{l}\text { Casa de Vegetação } \\
\text { Aberta }\end{array}$ & 28,4 & 66 & 26600 \\
\hline $\begin{array}{l}\text { Bancada de Preparo } \\
\text { de Substrato }\end{array}$ & 19,8 & 81 & 154 \\
\hline $\begin{array}{l}\text { Limpeza } \\
\text { Bandejas }\end{array}$ & 23,7 & 65 & 33000 \\
\hline $\begin{array}{l}\text { Avaliação de } \\
\text { Experimental e } \\
\text { Limpeza de Mudas }\end{array}$ & 22,3 & 70 & 40000 \\
\hline
\end{tabular}

\subsection{Análise das condições de trabalho}

A estrutura do viveiro florestal é composta por um laboratório com área para preparação de amostras, uma sala de aula, um ambiente destinado às análises de sementes e sala de germinação, três casas de vegetação, uma casa de sombra, linhas para rustificação e expedição de mudas, ambiente para trabalho em tubetes, entre outras benfeitorias. Devido a constantes experimentos desenvolvidos em casas de vegetação ou casas de sombra, os trabalhadores passam parte considerável do dia nessas áreas.

A casa de sombra é o local destinado para alocação das mudas em período anterior a rustificação, é composta por linhas de grades para tubetes de 30 centímetros de altura. Essa altura obriga os trabalhadores à no momento de executar qualquer atividade com as mudas, adotarem uma postura inadequada, necessitando extremo desvio da coluna para manusear os tubetes.

$\mathrm{Na}$ casa de vegetação totalmente fechada, as bancadas de trabalho para microstacas, assim como as bancadas de tubetes estão dispostas a 0,80 metros do chão, totalizando 0,95 metros com as bandejas, enquanto que na casa de vegetação aberta lateralmente, as bandejas são distribuídas no chão. A não padronização de distribuição de bancadas exige que os trabalhadores se adaptem a diferentes realidades, assumindo posturas inadequadas para manusear as mudas, forçando partes do corpo em excesso, como coluna vertebral, punhos e pescoço.

Os principais fatores presentes nas atividades do trabalhador que desencadeiam as lesões ou sensações de desconforto são posturas inadequadas, necessidade de aplicação de força, velocidade e aceleração do movimento, repetitividade, duração, tempo de recuperação e esforço dinâmico pesado. Estas condições associadas às características ambientais como calor, frio, iluminamento e ruído e ainda fatores adicionais como estresse, organização do trabalho e carga de trabalho potencializam as ocorrências das doenças causadas pelo trabalho [21]. 
Uma importante consideração em relação às casas de vegetação, bem como a casa de sombra é quanto a presença de sistemas de irrigação, importantes para suprir a necessidade hídrica das mudas cultivadas. Na casa de sombra, esse sistema é disposto a 1,70 metros de altura do solo, enquanto que na casa de vegetação fechada e na aberta lateralmente, dispunham-se a 2,10 metros e a 2,00 metros do solo respectivamente. Além disso, a altura empregada no sistema da casa de sombra pode causar dificuldade de circulação dos trabalhadores que apresentarem uma estatura muito alta. Essa preocupação com o ambiente durante a realização do trabalho pode tirar a atenção do trabalhador e interferir no resultado do produto negativamente.

Quando o organismo está desenvolvendo uma atividade fora da zona de conforto, o trabalhador pode sentir-se desconfortável, perdendo a motivação para o trabalho. A velocidade de reação para o desenvolvimento das tarefas diminui, ocorre também perda de precisão, perda de continuidade e diminuição da vigilância, o que torna o ambiente impróprio para o trabalho mental e, ainda, aumenta a incidência de acidentes [21].

As condições inadequadas de trabalho foram também observadas no setor de preparo de substrato e enchimento de tubetes. Manter a posição em pé, aliado a necessidade de cuidado na tarefa a ser realizada, exige que o trabalhador esteja atento durante todo o período de trabalho. Porém sua postura é prejudicada ao se deparar com bancadas não condizentes com a altura adequada, exigindo torção e inclinação da coluna a fim de executar o trabalho.

Por se tratar de uma área semiaberta, é de extrema importância o uso de EPIs que protejam o trabalhador contra poeiras do ambiente, além do pó do material usado para o preparo do substrato. Porém, o trabalhador não faz uso de luvas, máscaras ou qualquer outro tipo de proteção para a execução da atividade, estando em contato direto com esses condicionantes ambientais, além da possível inalação destes, causando danos a saúde.

O estudo a respeito dos fatores humanos e das condições de trabalho em qualquer empresa ou ambiente de trabalho é muito importante, pois objetiva desenvolver e aperfeiçoar métodos e técnicas operacionais, de forma a garantir condições mais seguras, confortáveis e saudáveis no ambiente de trabalho. O conhecimento das condições de vida e a busca constante de sua melhoria influenciam diretamente a satisfação do trabalhador, levando ao aumento de produtividade e qualidade do trabalho $[22 ; 6 ; 4]$.

\subsection{Recomendações}

Com base nas avaliações, sugerem-se as seguintes recomendações:
Implantação de bancadas de trabalho em conjunto com bancos de apoio adequados para trabalhadores envolvidos nas atividades de análise experimental, monda e limpeza de bandejas;

Instalação de uma varanda de sombra, de modo a permitir que o trabalho ao ar livre seja menos desgastante, permitindo ainda o trabalho em dias chuvosos;

Em relação a EPIs, é conveniente o uso de luvas e máscaras durante as atividades, a fim de melhorar a segurança e saúde dos trabalhadores, além da necessidade do uso de chapéus ou bonés e bloqueador solar, quando em contato com o sol;

Manutenção do processo de revezamento de funções, de modo a não sobrecarregar um trabalhador específico; e

Adequação da estrutura de casas de vegetação e casa de sombra (bancadas de mudas e sistema de irrigação) de acordo com medidas antropométricas dos trabalhadores do viveiro.

\section{Conclusão}

A análise ergonômica do trabalho possibilitou a verificação de situações que podem desencadear dor e desconforto nos trabalhadores. Todas as atividades analisadas apresentaram desconformidade quanto à postura empregada, sendo necessário a implantação de bancadas e bancos condizentes com as medidas antropométricas dos trabalhadores. Além disso, o revezamento de funções deve ser mantido, evitando aumento de repetitividade, buscando garantir a saúde e segurança dos trabalhadores.

Em relação a variáveis ambientais, para a temperatura apenas a casa de vegetação aberta apresentou valores acima do limite estabelecido pela norma. Já para a luminosidade somente a bancada de preparo de substrato apresentou valores aceitáveis com o recomendado e, por fim, os níveis de ruído encontrados em todos os locais analisados, condizem com o proposto pela norma.

\section{Agradecimentos}

LASERG/UFSM, Viveiro Florestal da UFSM e CAPES.

\section{Ergonomic Evaluation of a Forest Nursery of Santa Maria, RS}

ABSTRACT: The study was developed based on data collected in a forest nursery in Santa Maria, in order to perform a postural assessment of workers and environmental and structural conditions of the workplace. The evaluation took place from visual observations, and photographic records and posterior postural analysis by RULA method by Software Ergolândia. Still, we used an informal interview and COUTO ergonomics census 
for measurements about the nursery workers. Chemical analysis showed that the postures used in all activities assessed in the nursery present inadequate, resulting in level 3 RULA, requiring ergonomic intervention, and are causing pain and discomfort especially in the spine, neck, arms and legs of workers. The studied working environment was also not conducive to adequate for the tasks, causing discomfort and dissatisfaction among workers. Thus, to improve the environment, health and safety, we recommend the use of benches that allow correct postures for the execution of activities, use of PPE during operations, avoid carrying excessive loads, while maintaining the relay functions, decreasing the risk of injury from repetitive activities.

Keywords: Postural analysis; RULA; Safety.

\section{Referências}

[1] ASSOSIAÇÃO BRASILEIRA DE PRODUTORES DE FLORESTAS PLANTADAS ABRAF. Anuário Estatístico da ABRAF: Ano base 2011. 2012.

[2] WALKER, et al. Viveiro florestal: evolução tecnológica e legalização. Revista Verde. Mossoró, Rio Grande do Norte, Brasil, 2011.

[3] BRITO, P.C. de. Análise de fatores ergonômicos em Atividades de implantação florestal. Dissertação (Mestrado em Ciências Florestais)Universidade Estadual do Centro-Oeste- UNICENTRO, Irati, PR, 2012.

[4] FIEDLER, et al. Avaliação da carga de trabalho físico exigido em operações de produção de mudas ornamentais no Distrito Federal: Estudo de Caso. Sociedade de Investigações Florestais. Revista Árvore, Viçosa- Minas Gerais, 2007.

[5] FIEDLER, N.C.; VENTUROLI, F.; MINETTI, L.J. Análise de fatores ambientais em marcenarias no Distrito Federal. Revista Brasileira de Engenharia Agrícola e Ambiental. Campina Grande, 2006

[6] IIDA, I. Ergonomia; projeto e produção. São Paulo: Editora Edgard Blucher, 2016

[7] MCATAMNEY, L.; CORLETT, N. Rapid Upper Limb Assessment (RULA) In N. Stanton, A. Hedge, K. Brookhuis, E. Salas \& H. Hendrick (Eds.), Handbook of Human factors and Ergonomics Methods. 2005.

[8] NBR 5413- Norma Brasileira: Iluminância de interiores. ABNT- Associação Brasileira de Normas Técnicas. Disponível em: < http://www.abnt.org.br/ >. 13 pag.

[9] NBR 10152- Norma Regulamentadora: Níveis de Ruído para conforto acústico. ABNT- Associação Brasileira de Normas Técnicas. Disponível em: < http://www.abnt.org.br/ >. 13 pag.

[10] NR15- Norma Regulamentadora: Atividades e condições insalubres. ABNTAssociação Brasileira de Normas Técnicas. Disponível em: < http://www.guiatrabalhista.com.br/legislacao/nr/nr15.htm>.

[11] COUTO, H. A. Ergonomia aplicada ao trabalho- conteúdo básico- guia prático. Belo Horizonte: Editora ERGO, 2007.
[12] PINHEIRO, A. K. S.; FRANÇA, M. B. A. Ergonomia aplicada à anatomia e fisiologia do trabalhador. Goiânia: AB Ed., 2006. 165p.

[13] DUL, J.; WEERDMEESTER, B. Ergonomia prática. São Paulo: Editora Edgard Blücher LTDA. 1998.

[14]VOSNIAK, J. Análise de Variáveis Ergonômicas em Operações de Implantação Florestal. 2009. Dissertação (Mestrado em Ciências Florestais) UNICENTRO, Universidade do Centro Oeste. Irati, 2009.

[15] SILVA, E. P.; MINETTE, L. J.; SOUZA, A. P. Análise ergonômica do trabalho de coveamento semimecanizado para o plantio de eucalipto. Scientia Forestalis. Piracicaba, 2007.

[16] FIEDLER, et al. Avaliação Biomecânica dos Trabalhadores em Marcenarias no Distrito Federal. Ciência Florestal, Santa Maria, 2003.

[17] FERREIRA, P. C. Avaliação ergonômica de algumas operações florestais no município de Santa Bárbara-MG. 2006. 77 p. Dissertação (Mestrado em Meio Ambiente e Sustentabilidade) - Centro Universitário de Caratinga - UNEC, Caratinga, MG. 2006.

[18] ALVES, et al. Avaliação biomecânica dos trabalhadores nas atividades de propagação de Eucalyptus spp. Ciência Florestal, Santa Maria, 2001.

[19] SILVEIRA, F. S. A. Avaliação ergonômica das atividades de coveamento manual, coveamento semimecanizado, plantio manual e aplicação de corretivo do solo na implantação florestal de eucalipto. Dissertação (Mestrado em Meio Ambiente e Sustentabilidade)- Centro Universitário de CaratingaUNEC, Caratinga, Minas Gerais. 2006.

[20] ALVES, J.U. Análise ergonômica da produção de mudas de eucalipto em Viveiro, no Vale do Rio Doce, MG. Tese (Doutorado em Ciência florestal)Universidade Federal de Viçosa. Viçosa- Minas gerais, 2004.

[21] ALVES, et al. Avaliação do ambiente de trabalho na propagação de Eucalyptus spp. Revista Brasileira de Engenharia Agrícola e Ambiental. Campina Grande, 2002.

[22] GRANDJEAN, E. Manual de ergonomia: adaptado ao trabalho do homem. 4 ed. Trad.

João Pedro Stein. Porto Alegre: Artes médicas, 1998. 